\title{
RESEARCH OF ROLLING REGIMES AND MECHANICAL PROPERTIES OF COLD- ROLLED, ANNEALED AND WELDED SEMI-FINISHED PRODUCTS FROM EXPERIMENTAL ALLOYS OF AI-Mg SYSTEM, ECONOMICALLY ALLOYED BY SCANDIUM
}

\author{
Baranov V.N. ${ }^{1}$, Sidelnikov S.B. ${ }^{1}$, Bezrukih A.I. ${ }^{1}$, Zenkin E.Y. ${ }^{2}$ \\ ${ }^{1}$ Siberian federal university, Krasnoyarsk \\ ${ }^{2}$ «RUSAL Bratsk Aluminum Smelter» JSC, Bratsk
}

Research results of thermodeformation machining of flat ingots from experimental aluminium alloys, containing magnesium, scandium, rare-earth and transition metals have been represented. Relevance of the work aimed at creating new alloys system Al-Mg, alloyed by scandium, and technologies for obtaining deformed semi-finished products from them using metal forming operations have been shown. Regimes of hot and cold sheet rolling for obtaining strips with thickness 1-3 mm from these alloys were calculated and experimentally tested. Experimental research included the following steps: preparation of flat slabs with dimensions $28 \times 150 \times 300 \mathrm{~mm}$ for rolling; hot rolling with temperature $450{ }^{\circ} \mathrm{C}$ with total draw ratio about 6; cold rolling with total draw ratio about 5; annealing of cold-deformed semi-finished products at temperature $350{ }^{\circ} \mathrm{C}$ within 3 hours; argon-arc welding of the obtained strips along and across the direction of deformation; Intergranular corrosion test; Evaluation of mechanical properties of the samples. As a result of research nature and degree of corrosion destruction have been studied and Mechanical properties of deformed, annealed and welded semi-finished products from experimental alloys have been determined. It is established that they have a high level of strength and plastic properties of the metal along, across and at an angle $45^{\circ}$ relative to the direction of rolling. So tensile strength reaches value 500-520 MPa for deformed samples, yield strength of metal 435$470 \mathrm{MPa}$, relative elongation 4,8-6,7 \%, and for annealed samples the values of the relative elongation increase and can reach 14-14,5 \% At sufficiently high yield strength 357-369 MPa. Tests for intergranular corrosion of samples after welding showed high corrosion resistance of welded joints, The strength of the welded seam is $0,75-0,85$ of the strength of the base metal. The results of research can be recommended for the development of technology for the manufacture of parts from flat products, which including welded joints.

Keywords: Aluminum alloys, scandium, zirconium, rolling, welding, intergranular corrosion, mechanical properties, force and moment of rolling. 


\section{УДК 621.777}

Исследование режимов прокатки и механических свойств холоднокатаных, отожженных и сварных полуфабрикатов из опытных сплавов системы Al-Mg, экономнолегированных скандием

\section{Баранов В.Н. ${ }^{1}$, Сидельников С.Б. ${ }^{1}$, Безруких А.И. ${ }^{1}$, Зенкин Е.Ю. ${ }^{2}$}

\section{${ }^{1}$ Сибирский федеральный университет, г. Красноярск ${ }^{2}$ ОАО «РУСАЛ Братский алюминиевый завод», г. Братск}

Приведены результаты исследований термодеформационной обработки плоских слитков из опытных алюминиевых сплавов, содержащих магний, скандий, редкоземельные и переходные металлы. Показана актуальность работ, направленных на создание новых сплавов системы Al-Mg, легированных скандием, и технологий получения из них деформированных полуфабрикатов с помощью операций обработки металлов давлением. Рассчитаны и экспериментально опробованы режимы горячей и холодной листовой прокатки для получения полос толщиной 1-3 мм из этих сплавов. Экспериментальные исследования включали следующие этапы: подготовку плоских слитков размерами $28 \times 150 \times 300$ мм к прокатке; горячую прокатку при температуре $450{ }^{\circ} \mathrm{C}$ с суммарной вытяжкой порядка 6; холодную прокатку с суммарной вытяжкой порядка 5; отжиг холоднодеформированных полуфабрикатов при температуре $350{ }^{\circ} \mathrm{C}$ в течение 3 часов; аргонодуговую сварку полученных полос вдоль и поперек направления деформации; испытания на межкристаллитную коррозию; оценку механических свойств образцов. В результате проведения исследований изучен характер и степень коррозионного разрушения и определены механические свойства деформированных, отожженных и сварных полуфабрикатов из опытных сплавов. Установлено, что они имеют высокий уровень прочностных и пластических свойств металла вдоль, поперек и под углом $45^{\circ}$ относительно направления прокатки. Так временное сопротивление разрыву достигает для деформированных образцов 500-520 МПа, предел текучести металла 435-470 МПа, относительное удлинение 4,8-6,7 \%, а для отожженных образцов значения относительного удлинения увеличиваются и могут достигать 14-14,5 \% при достаточно высоких значениях предела текучести 357-369 МПа. Испытания на межкристаллитную коррозию образцов после сварки показали высокую коррозионную стойкость сварных соединений, при этом прочность сварного шва составляет 0,75-0,85 от прочности основного металла. Результаты 
исследований можно рекомендовать для разработки технологии изготовления деталей из плоского проката, в том числе и со сварными соединениями.

Ключевые слова: алюминиевые сплавы, скандий, цирконий, прокатка, сварка, межкристаллитная коррозия, механические свойства, усилие и момент прокатки.

\section{Введение}

Задачи глубокой переработки алюминия с целью расширения сферы его применения требуют создания новых сплавов, имеющих повышенные эксплуатационные свойства, и являются актуальными для развития металлургической отрасли [1]. Анализ научнотехнической литературы показал [2-10], что сплавы системы $\mathrm{Al}-\mathrm{Mg}$, легированные редкоземельными и переходными металлами с целью достижения повышенных прочностных и коррозионных свойств, могут стать базовыми для решения этих задач.

Наиболее широкое распространение в промышленности получили сплавы с содержанием магния от 1 до 5 \%, при этом они структурно стабильны при комнатной и повышенной температуре и применяются в народном хозяйстве в таких отраслях, как транспортное машиностроение, химическая, нефтяная и газовая промышленность, сельскохозяйственные отрасли для изготовления каркасных конструкций, автомобильных и железнодорожных цистерн, различных емкостей, сосудов, работающих под давлением, трубных конструкций. Увеличение содержания магния свыше 5-6\% приводит к ухудшению коррозионной стойкости сплава. Высоколегированные сплавы этой группы применяются, в основном, в ракетной и космической технике. Из них производят все виды деформированных полуфабрикатов: поковки, прессованные изделия (прутки, профили, панели, трубы) и проволоку (заклепочную и сварочную). Особое значение для авиа- и судостроения имеют изделия в виде листов и плит, получаемые по технологии горячей и холодной прокатки [11]

Сотрудниками ОК РУСАЛ совместно с учеными института цветных металлов и материаловедения Сибирского федерального университета проведен ряд исследовательских и опытно-конструкторских работ, направленных на разработку новых сплавов системы Al-Mg с различным содержанием скандия, редкоземельных и переходных металлов и технологий их обработки [12-14]. В результате были изготовлены плоские слитки опытных сплавов, в которых содержание дорогостоящего скандия составляло 0,10$0,14 \%$.

В перспективе плоские слитки из новых сплавов, легированных скандием, предназначены для получения листового проката для автомобиле- и судостроения. Однако 
для корректировки химического состава сплавов, получения комплекса заданных механических и коррозионных свойств, а также реализации технологических режимов горячей и холодной прокатки необходимо было исследовать свойства листовых полуфабрикатов в различном состоянии.

\section{Методика проведения исследований}

Методика исследований состояла в следующем. Слитки опытных сплавов размерами 30x150x300 мм после гомогенизации подвергали механической обработке до толщины 28 мм. По рассчитанным маршрутам при температуре $450{ }^{\circ} \mathrm{C}$ на прокатном стане MDM ARIETE LS 400x240 (табл. 1) проводили горячую прокатку слитков опытных сплавов до толщины заготовок 10 и 5 мм. Далее прокатывали каждую из полученных заготовок в холодном состоянии до толщины 3 и 1 мм. После прокатки полосы отжигали при температуре $350{ }^{\circ} \mathrm{C}$ в течение 3 часов. На каждом из технологических переделов отбирали темплеты и изготавливали из них образцы для механических испытаний.

Таблица 1 - Техническая характеристика прокатного стана MDM ARIETE LS 400x240

\begin{tabular}{|l|c|}
\hline \multicolumn{1}{|c|}{ Наименование параметра } & Величина параметра \\
\hline Мощность электродвигателя, кВт & $18,5+2,2$ \\
\hline Напряжение питания сети трехфазное, В & 380 \\
\hline Частота тока, Гц & 50 \\
\hline Длина бочки валков, мм & 400 \\
\hline Диаметр валков, мм & 240 \\
\hline Максимальный развод валков, мм & 70 \\
\hline Максимальная угловая скорость валков, рад/с & 1,83 \\
\hline Максимальное усилие прокатки, МН & 1,12 \\
\hline Максимальный момент прокатки, МН·м & 0,008 \\
\hline Габаритные размеры, мм & $1900 \times 750 \times 2150$ \\
\hline Масса, кг & 3950 \\
\hline
\end{tabular}

Для исследования свойств сварного шва полученные полосы сваривали вдоль и поперек направления деформации (рис. 1) с помощью аргонодуговой сварки полос с присадочной проволокой из сплава 1570. 

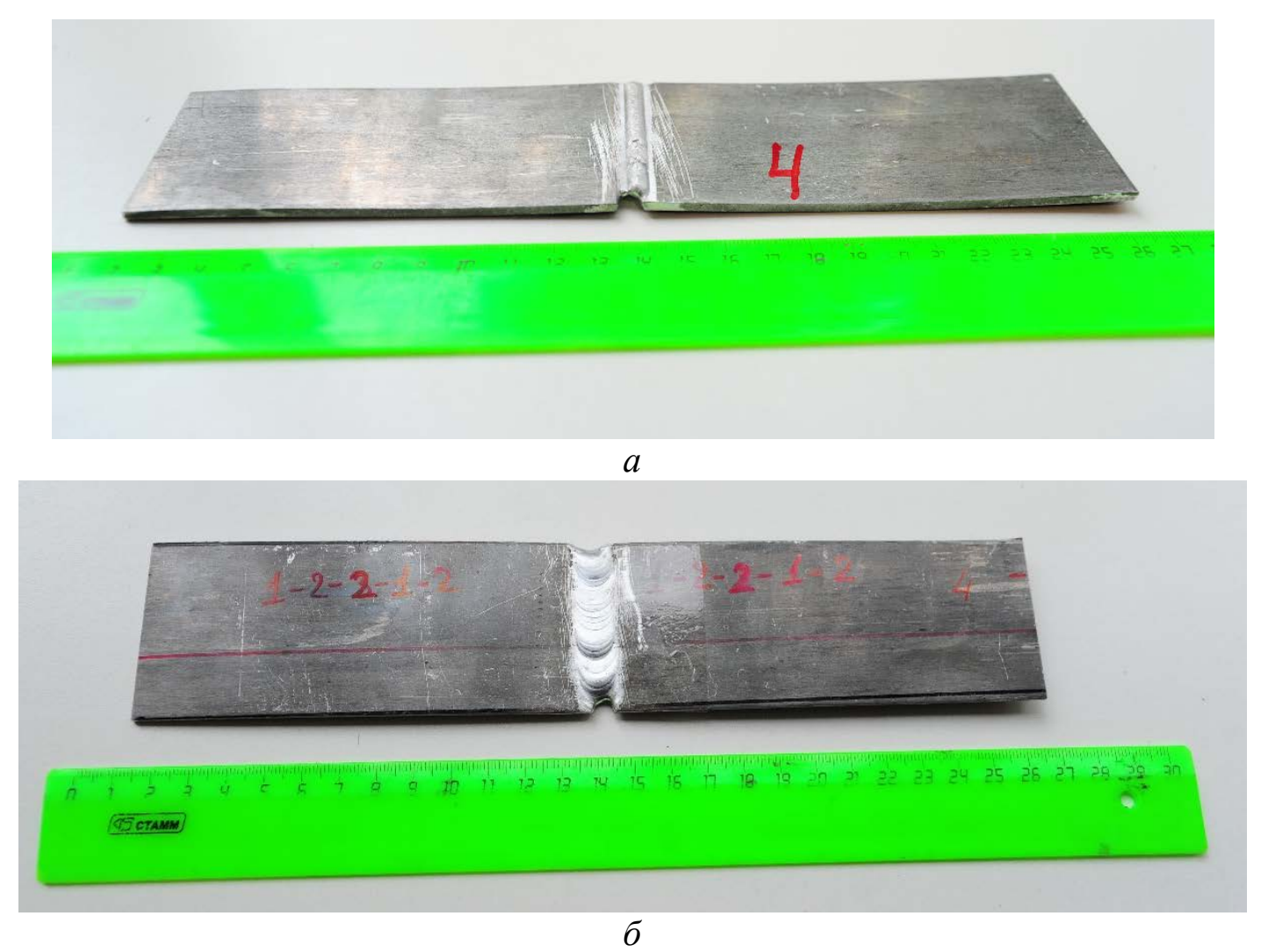

Рис. 1. Сварная заготовка со стороны сварного шва (a) и обратной стороны (б)

Для оценки характера и степени коррозионного разрушения опытных сплавов в соответствии с ГОСТ 9.021-74 были проведены ускоренные испытания на межкристаллитную коррозию (МКК). Испытаниям подвергали 3 типа образцов: деформированные, со сварным швом вдоль и поперек прокатки (рис. 2). Со всех сторон образцы омывались раствором содержащем: 1 н. раствор хлористого натрия и 0,3 \% перекиси водорода (58 г/л $\mathrm{NaCl}+10$ мл/л 33\%-ного раствора $\left.\mathrm{H}_{2} \mathrm{O}_{2}\right)$, температура раствора составляла $18-25{ }^{\circ} \mathrm{C}$, продолжительность испытания 24 ч.

Образцы перед испытанием на МКК обезжиривали изопропиловым спиртом и высушивали фильтровальной бумагой. Далее проводили травление в течении 2 минут в растворе, содержащем 50 мл азотной кислоты (70\%-ной), 5 мл плавиковой кислоты (48\%ной) и 945 мл воды, при температуре раствора $95 \pm 3{ }^{\circ} \mathrm{C}$; затем образцы промывали в холодной воде и осветляли в 25-30\%-ном растворе азотной кислоты, после чего еще раз промывали и высушивали фильтровальной бумагой.

После окончания испытания образцы промывали под проточной водой и высушивали в печи при температуре $100 \pm 5^{\circ} \mathrm{C}$ в течение 5 минут.

Оценку образцов металлографическим методом и испытания на растяжение плоских образцов проводили не позднее 7 суток после окончания коррозионных испытаний. 


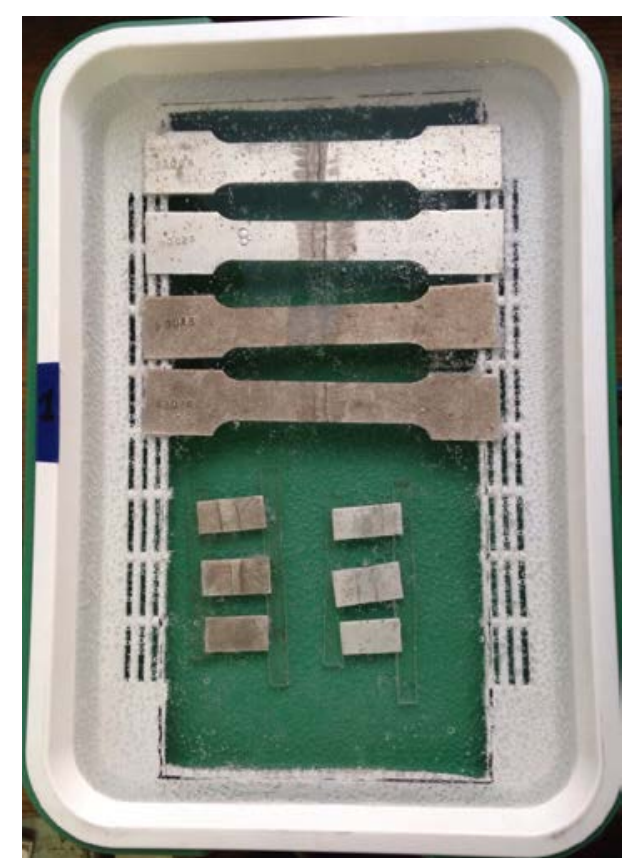

$a$

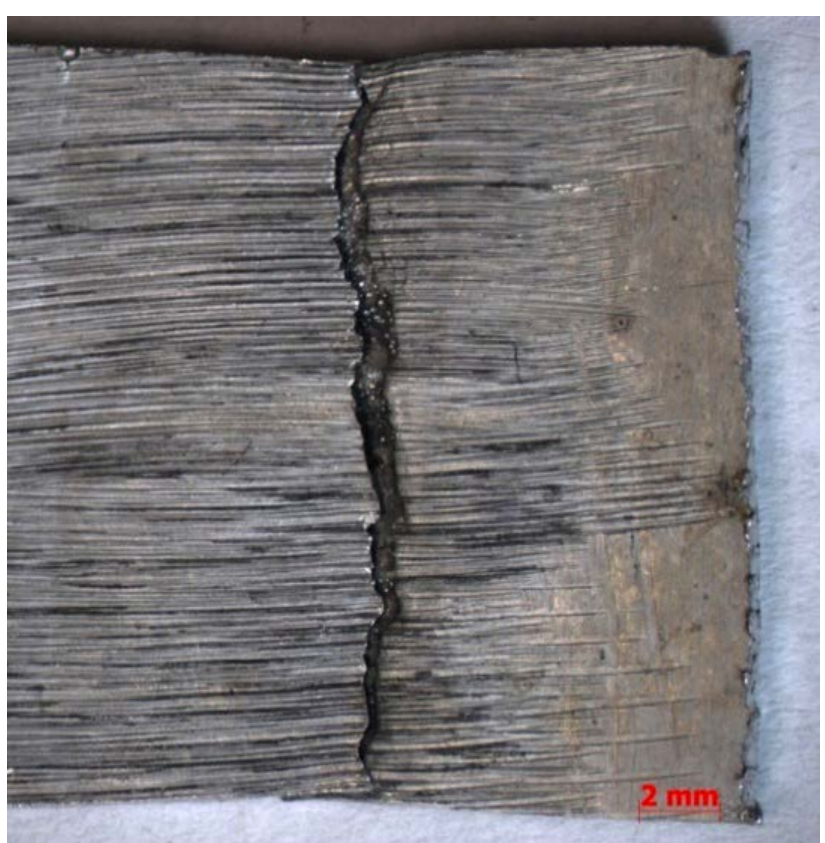

6

Рис. 2. Расположение образцов для испытаний на межкристаллитную коррозию (a) и характерная макроструктура сварного образца после МКК и испытания на растяжение в месте разрыва (б), ×1.6

Шлифы для металлографического анализа изготавливали по ГОСТ 1778-70 и подвергали исследованию на микроскопе Axio Observer A1.m, Carl Zeiss. Металлографическим методом был определен характер коррозии на образцах из исследуемых сплавов, максимальное значение глубины МКК и распространение коррозии по краю шлифа.

\section{Результаты и их обсуждение}

Результаты исследований режимов горячей прокатки и энергосиловых параметров прокатки показаны на рис. 3.

Анализ процесса горячей прокатки при суммарной вытяжке порядка 6 показал, что снижение температуры заготовки может привести к нарушению ограничений по моменту прокатки, особенно, если сплав будет обладать повышенными прочностными характеристиками. В связи с эти необходимо подогревать заготовку в процессе прокатки или плакировать ее чистым алюминием.

Анализ деформационных и энергосиловых параметров холодной прокатки (рис. 4) показал, что при суммарной вытяжке порядка 5 значения усилия и момента прокатки не достигают допустимых, а коэффициент вытяжки по проходам изменяется плавно, без 
резких скачков. При холодной прокатке учитывалось упрочнение металла в процессе обработки, поэтому единичные коэффициенты вытяжки снижали к последним проходам.

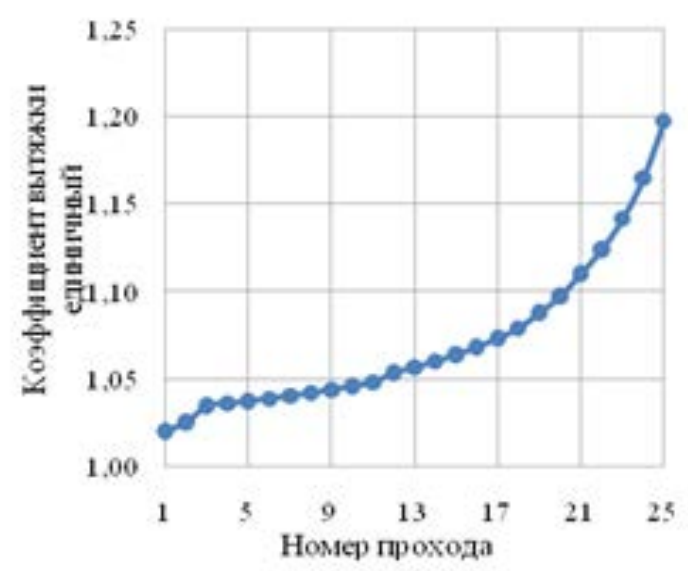

$a$

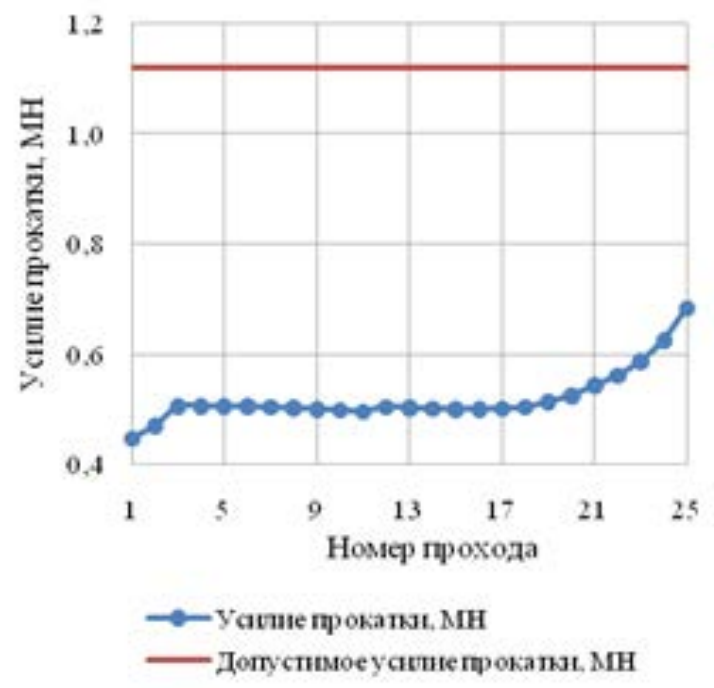

6

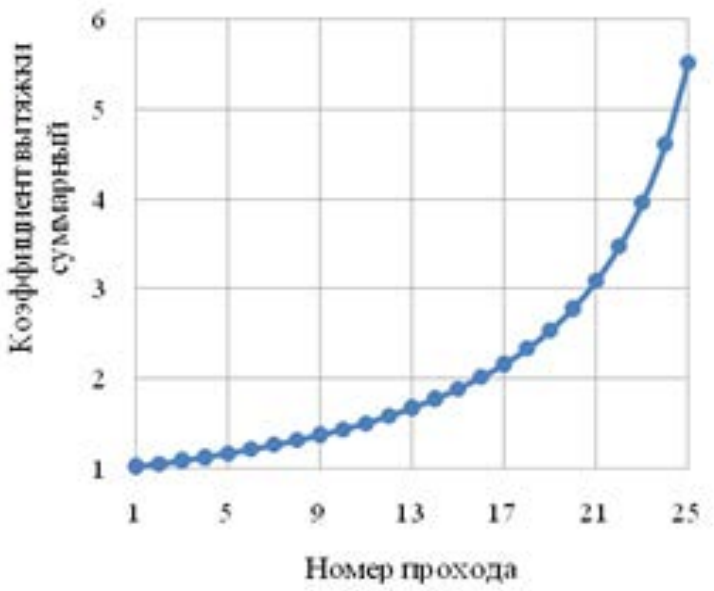

6

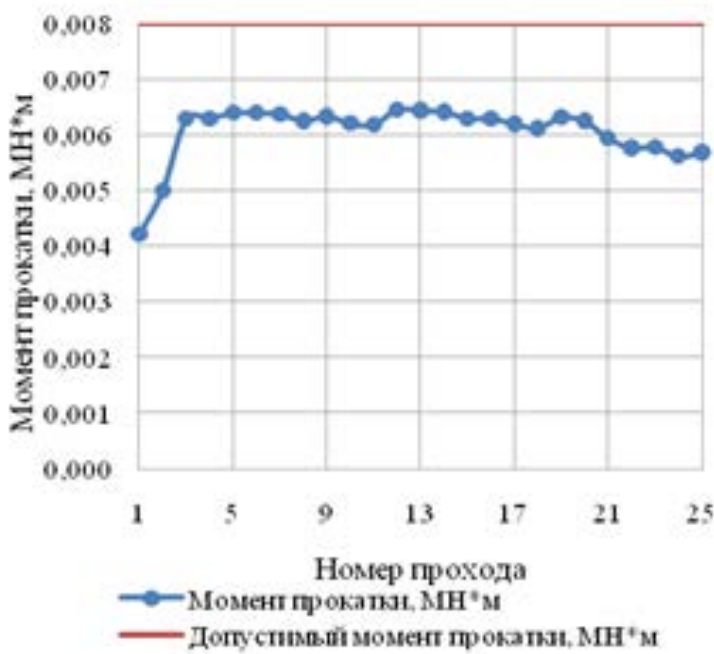

\&

Рис. 3. Изменение единичного (a) и суммарного (б) коэффициентов вытяжки, усилия (в) и момента (2) горячей прокатки для рассчитанного маршрута по проходам

Тем не менее, в процессе деформации происходило интенсивное упрочнение металла, что приводило к увеличению усилия холодной прокатки в 8 - 10 проходах, что следует учитывать при практической реализации технологии обработки таких сплавов в производственных условиях.

Испытания на межкристаллитную коррозию образцов опытных сплавов показали высокую устойчивость к данному виду коррозии: в основном металле большинства образцов не было обнаружено элементов МКК, и лишь в некоторых образцах и сварных швах выявлены ее единичные участки глубиной до $6-28$ мкм, протяженностью от 2 до 37 
мкм. Разрушение опытных сварных образцов при механических испытаниях произошло в основном по границе зоны сплавления (см. рис.2).

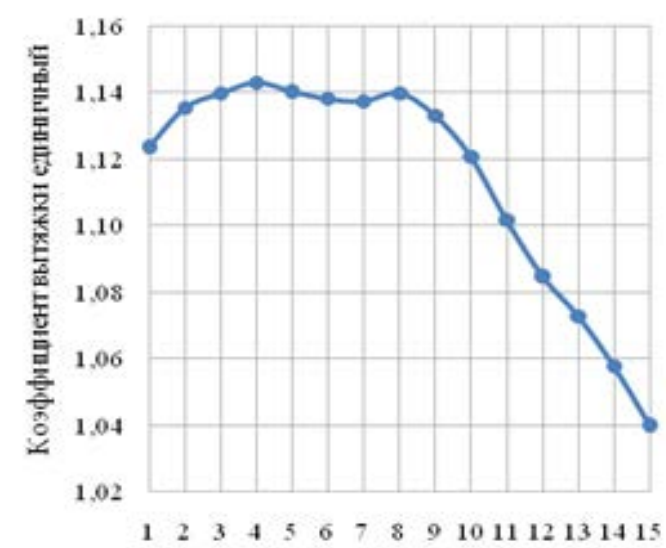

Номер прохода

$a$

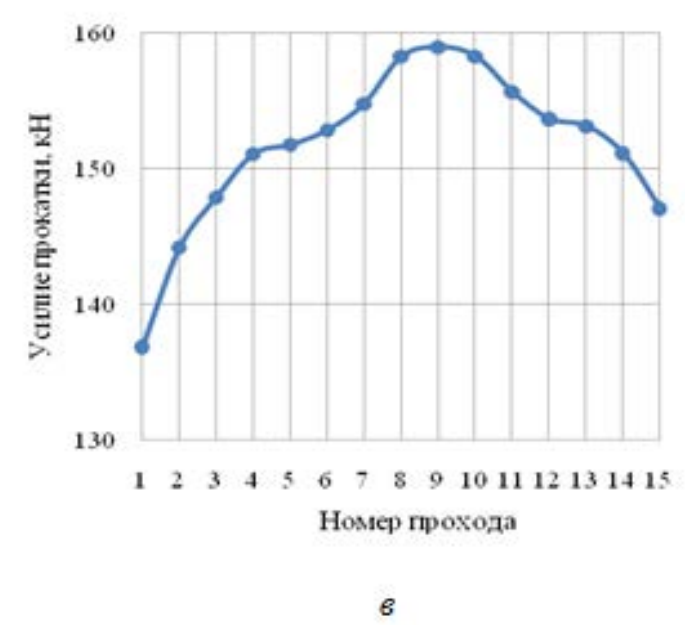

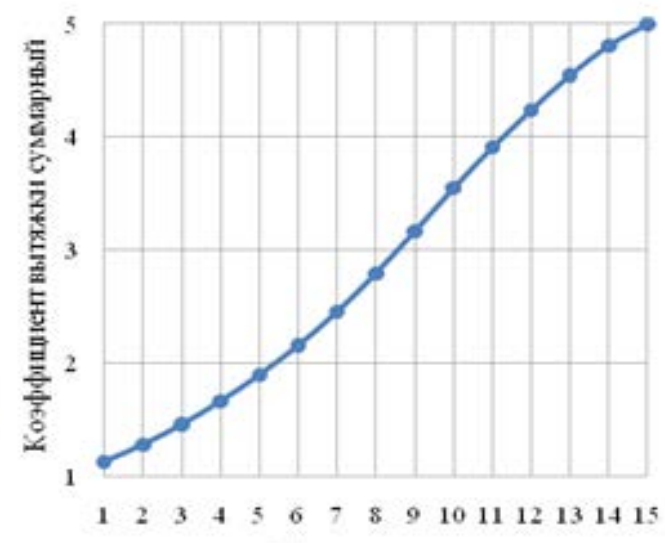

Номер прохода

$\sigma$

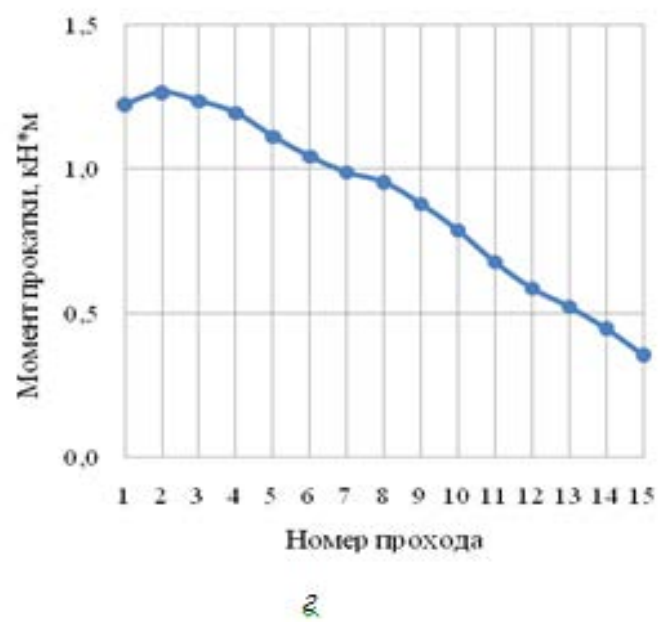

Рис. 4. Изменение единичного (a) и суммарного (б) коэффициентов вытяжки, усилия (в) и момента (2) холодной прокатки для рассчитанного маршрута по проходам

Исследования механических свойств металла после прокатки и отжига, а также после сварки и коррозии, методом растяжения проводили на испытательной машине LFM400 усилием 400 кН в соответствие с ГОСТ 1497-84. Результаты испытаний механических свойств образцов из опытных сплавов с содержанием скандия от 0,10-0,12\% приведены в табл.2.

Образцы вырезали из полученных прокаткой полос толщиной 3 мм в трех направлениях: вдоль направления прокатки (способ 1); поперек направления прокатки (способ 2); под углом $45^{\circ}$ относительно направления прокатки (способ 3). Образцы 4-6 сплава 4 (см. табл. 2) исследовали в холоднодеформированном состоянии без отжига. Механические свойства сварного шва изучали на образцах, полученных способами 1 и 2. 
Таблица 2 - Механические свойства образцов из опытных сплавов

\begin{tabular}{|c|c|c|c|c|c|c|c|}
\hline \multirow{2}{*}{$\begin{array}{c}\text { Номер } \\
\text { сплава/ }\end{array}$} & \multirow{2}{*}{$\begin{array}{c}\text { Способ } \\
\text { вырезки }\end{array}$} & \multicolumn{6}{|c|}{ Механические свойства образцов } \\
\cline { 3 - 8 } & образцов & \multicolumn{2}{|c|}{ после прокатки и отжига } & \multicolumn{3}{c|}{ после сварки и коррозии } \\
\cline { 3 - 8 } & $\sigma_{\text {в }}$, МПа & $\sigma_{0,2}$, МПа & $\delta, \%$ & $\sigma_{\text {в }}$, МПа & $\sigma_{0,2}$, МПа & $\delta, \%$ \\
\hline $1 / 1$ & 1 & 443 & 358 & 6,0 & 362 & 246 & 6 \\
\hline $1 / 2$ & 2 & 444 & 368 & 10,6 & 353 & 293 & 3,3 \\
\hline $1 / 3$ & 3 & 440 & 357 & 14,5 & - & - & - \\
\hline $2 / 1$ & 1 & 453 & 365 & 8,5 & 361 & 250 & 6 \\
\hline $2 / 2$ & 2 & 446 & 369 & 14,0 & 334 & 245 & 2,6 \\
\hline $2 / 3$ & 3 & 434 & 357 & 14,0 & - & - & - \\
\hline $3 / 1$ & 1 & 452 & 359 & 8,9 & 351 & 242 & 5,7 \\
\hline $3 / 2$ & 2 & 460 & 375 & 12,9 & 333 & 240 & 3,3 \\
\hline $3 / 3$ & 3 & 441 & 357 & 14,2 & - & - & - \\
\hline $4 / 1$ & 1 & 449 & 357 & 9,9 & 344 & 250 & 5,8 \\
\hline $4 / 2$ & 2 & 463 & 383 & 11,2 & 339 & 246 & 3,1 \\
\hline $4 / 3$ & 3 & 443 & 360 & 13,4 & - & - & - \\
\hline $4 / 4^{*}$ & 1 & 520 & 472 & 4,8 & 354 & 236 & 4,3 \\
\hline $4 / 5^{*}$ & 2 & 524 & 450 & 5,7 & 327 & 230 & 4,6 \\
\hline $4 / 6^{*}$ & 3 & 507 & 435 & 6,7 & - & - & - \\
\hline
\end{tabular}

Примечание: * - неотожженные образцы

Анализ механических свойств полученных полуфабрикатов показывает, что уровень прочностных и пластических свойств достаточно высок, при этом временное сопротивление разрыву достигает для деформированных образцов 500-520 МПа, предел текучести металла 435-470 МПа, а относительное удлинение 4,8 - 6,7\%. Применение отжига позволяет в зависимости от химического состава сплава получить высокие пластические свойства (значения относительного удлинения увеличиваются и достигают 14 -14,5 \%) при достаточно высоких значениях предела текучести (357-369 МПа). Наряду с высокой стойкостью к коррозии сварных образцов из опытных сплавов, они также характеризуются высокими значениями прочностных характеристик, при этом прочность сварного шва составляет $0,75-0,85$ от прочности основного металла.

\section{Заключение}

Таким образом, определены режимы горячей и холодной прокатки полос из опытных сплавов системы $\mathrm{Al}-\mathrm{Mg}$ c различным содержанием скандия и проведены экспериментальные исследования по получению полос из этих сплавов толщиной 1 и 3 мм. Исследования механических свойств этих полос в деформированном и отожженном состоянии позволили установить высокий уровень прочностных и пластических свойств металла в продольном, поперечном направлениях и под углом $45^{\circ}$ относительно направления прокатки. Испытания на межкристаллитную коррозию образцов после сварки показали высокую коррозионную стойкость сварных соединений, при этом прочность 
сварного шва составляет 0,75-0,85 от прочности основного металла. Указанные результаты исследований дают возможность рекомендовать опытные сплавы для практического применения в различных отраслях промышленности для изготовления деталей из плоского проката, в том числе и со сварными соединениями.

Статья подготовлена с использованием результатов работ, выполненных в ходе проекта 03.G25.31.0265 «Разработка экономнолегированных высокопрочных Al-Sc сплавов для применения в автомобильном транспорте и судоходстве» в рамках Программы реализации комплексных проектов по созданию высокотехнологичного производства, утвержденных постановлением Правительства РФ от 9 апреля 2010 г. №218.

\section{Библиографический список}

1. Горбунов Ю.А. Роль и перспективы редкоземельных металлов в развитии физикомеханических характеристик и областей применения деформируемых алюминиевых сплавов./ Журнал Сибирского федерального университета. Серия: Техника и технологии. 2015. T. 8. № 5. C. $636-645$.

2. Chunchang Shi, Liang Zhang, Guohua Wu, Xiaolong Zhang, Antao Chen, Jiashen Tao. Effects of Sc addition on the microstructure and mechanical properties of cast Al-3Li-1.5Cu0.15Zr alloy. - Materials Science \& Engineering. - 2017. - A680. - p. 232-238.

3. Pedro Henrique R. Pereiraa, Ying Chun Wang, Yi Huang, Terence G. Langdon. Influence of grain size on the flow properties of an Al-Mg-Sc alloy over seven orders of magnitude of strain rate. - Materials Science \& Engineering. - 2017. - A685. - p. 367-376.

4. S. Mondol, T. Alamb, R. Banerjee, S. Kumar, K. Chattopadhyay. Development of a high temperature high strength $\mathrm{Al}$ alloy by addition of small amounts of Sc and Mg to 2219 alloy. Materials Science \& Engineering. - 2017. - A687. - p. 221-231.

5. Mengjia Li, Qinglin Pan, Yunjia Shi, Xue Sun, Hao Xiang. High strain rate superplasticity in an Al-Mg-Sc-Zr alloy processed via simple rolling. - Materials Science \& Engineering. - 2017. A687.- p.298-305.

6. Yu. Buranova, V. Kulitskiy, M. Peterlechner, A. Mogucheva, R. Kaibyshev, S.V. Divinski, G. Wilde. Al3(Sc, Zr) - based precipitates in AleMg alloy: Effect of severe deformation- Acta Materialia. - 2017. - 124. - p. 210-224.

7. Иброхимов С.Ж. Влияние скандия на физико-химические свойства сплава АМг4 / С.Ж. Иброхимов, Б.Б. Эшов, И. Н. Ганиев, Н. Ф. Иброхимов // Известия Самарского научного центра Российской академии наук.- 2014. - т. 16 - №4. - С. 256-260. 
8. Иброхимов С. Ж. Окисление твёрдого алюминиево-магниевого сплава АМг4, легированного скандием / С.Ж. Иброхимов, Б.Б. Эшов, И.Н. Ганиев// Доклады академии наук республики Таджикистан. - 2013. - т. 56. - № 6. - С. 472-475.

9. Кузнецов Г.М. Особенности формирования структуры и свойств литейных Al-Mgсплавов, легированных скандием / Г.М. Кузнецов, П.П. Побежимов, Л.П. Нефедова, Е.В. Белов // Металловедение и термическая обработка металлов. ВИАМ. - 1996. - №6.

10. Дриц М. Е. О характере взаимодействия скандия с алюминием в богатой алюминием части системы. / М. Е. Дриц, Э.С. Каданер, Т.В. Добаткина, Н.И. Туркина //Изв. АН СССР. -1973. - № 4. - С. 213-217.

11. Сидельников С.Б., Константинов И.Л., Ворошилов Д.С. Технология прокатки: учебник. 3-е изд. - Красноярск: Сиб. федер.ун-т, 2016. - 180 с.

12. Якивьюк О.В., Сидельников С.Б., Довженко Н.Н. и др. Исследование технологичности обработки и свойств проката из алюминиевых сплавов системы $\mathrm{Al}-\mathrm{Mg}$, экономно легированных скандием. // Цветные металлы и минералы 2016: Сб. тезисов докладов. Красноярск, 2016, С.262-263.

13. Фролов В.А., Якивьюк О. В., Фролов В.Ф., Ворошилов Д.С. Свойства алюминиевых сплавов, экономно легированных скандием, после деформационного и термического воздействия // Сборник материалов XVII международной научно-технической уральской школы - семинара металловедов - молодых ученых .- 2016. - Часть 2. - С. 113-117.

14. Фролов В.А. Исследование механических свойств полуфабрикатов из алюминиевых сплавов, экономно легированных скандием // Инновационные процессы обработки металлов давлением: материалы 2 международной научно-практической конференции под ред. М.В. Чукина. Магнитогорск: Изд-во Магнитогорск. гос. техн. ун-та им. Г.И. Носова, 2016, C. 23-24.

\section{References}

1. Gorbunov Yu.A. The role and prospects of rare earth metals in the development of physicalmechanical characteristics and applications of deformable aluminum alloys/ Journal of Siberian Federal University. Engineering \& Technologies 5 - 2015. T. 8. № 5. p. 636 - 645.

2. Chunchang Shi, Liang Zhang, Guohua Wu, Xiaolong Zhang, Antao Chen, Jiashen Tao. Effects of Sc addition on the microstructure and mechanical properties of cast Al-3Li-1.5Cu0.15Zr alloy. - Materials Science \& Engineering. - 2017. - A680. - p. 232-238.

3. Pedro Henrique R. Pereiraa, Ying Chun Wang, Yi Huang, Terence G. Langdon. Influence of grain size on the flow properties of an Al-Mg-Sc alloy over seven orders of magnitude of strain rate. - Materials Science \& Engineering. - 2017. - A685. - p. 367-376. 
4. S. Mondol, T. Alamb, R. Banerjee, S. Kumar, K. Chattopadhyay. Development of a high temperature high strength Al alloy by addition of small amounts of Sc and Mg to 2219 alloy. Materials Science \& Engineering. - 2017. - A687. - p. 221-231.

5. Mengjia Li, Qinglin Pan, Yunjia Shi, Xue Sun, Hao Xiang. High strain rate superplasticity in an Al-Mg-Sc-Zr alloy processed via simple rolling. - Materials Science \& Engineering. - 2017. A687.- p.298-305.

6. Yu. Buranova, V. Kulitskiy, M. Peterlechner, A. Mogucheva, R. Kaibyshev, S.V. Divinski, G. Wilde. Al3(Sc, Zr) - based precipitates in AleMg alloy: Effect of severe deformation- Acta Materialia. - 2017. - 124. - p. 210-224.

7. Ibrokhimov S.Zh. Influence scandium on the physicochemical properties of the alloy AMg4 / S.Zh. Ibrokhimov, B.B. Eshov, I. N. Ganiev, N. F. Ibrokhimov // Proceedings of the Samara Scientific Center of the Russian Academy of Sciences.- 2014. - T. 16 - №4. - p. 256-260.

8. Ibrokhimov S.Zh. Oxidation of a hard aluminum-magnesium alloy AMg4, alloyed with scandium / S.Zh. Ibrokhimov, B.B. Eshov, I. N. Ganiev // Reports of the Academy of Sciences of the Republic of Tajikistan. - 2013. - T. 56. - № 6. - p. 472-475.

9. Kuznetsov G.M. Features of the formation of the structure and properties of cast Al-Mg alloys doped with scandium / G.M. Kuznetsov, P.P. Pobezhimov, L.P. Nefedova, E.V. Belov // Metallurgy and heat treatment of metals. VIAM. - 1996. - №6.

10. Drits M.E. On the nature of the interaction of scandium with aluminum in the aluminum-rich part of the system. / M.E. Drits, E.S. Kadaner, T.V. Dobatkina, N.I. Turkina //Bulletin. AS USSR. -1973. - № 4. - p. 213-217.

11. Sidelnikov S.B., Konstantinov I.L., Voroshilov D.S. Rolling technology: textbook. 3rd edition. - Krasnoyarsk: SibFU, 2016. - 180 p.

12. Yakivyuk O.V., Sidelnikov S.B., Dovzhenko N.N. and others. Research of manufacturability of processing and properties of hire from aluminum alloys of system Al-Mg, economically alloyed with scandium // Non-ferrous metals and minerals 2016: Collection of abstracts. Krasnoyarsk, 2016, p. 262-263.

13. Frolov V.A., Yakivyuk O. V., Frolov V.F., Voroshilov D.S. Properties of aluminum alloys economically alloyed with scandium, after deformation and thermal exposure // Collection of materials XVII international scientific and technical Ural school - a seminar of metal scientists young scientists - 2016. - Part 2. - p. 113-117.

14. Frolov V.A. Research of mechanical properties of semi-finished products from aluminum alloys economically alloyed with scandium // Innovative processes of metal forming: materials 2 of the international scientific and practical conference, ed. M.V. Chukin. Magnitogorsk: Edition of Magnitogorsk. State Technical University named after G.I. Nosov, 2016, p. 23-24. 